\title{
Angiomyofibroblastoma mimicking an inguinal hernia: a challenging diagnosis in a male patient
}

\author{
Laura Banias ${ }^{1}$, Simona Gurzuㄹ, loan Jung ${ }^{1}$, Cristian Borz ${ }^{2}$ \\ ${ }^{1}$ Department of Pathology, University of Medicine, Pharmacy, Sciences and Technology, Tirgu-Mureş, Romania \\ ${ }^{2}$ Department of Surgery, University of Medicine, Pharmacy, Sciences and Technology, Tirgu-Mureş, Romania
}

Adv Dermatol Allergol 2019; XXXVI (2): 223-226

DOI: https://doi.org/10.5114/ada.2019.84597

\begin{abstract}
Introduction: Angiomyofibroblastoma is a rare benign myofibroblastic neoplasm which mainly occurs in the soft tissues of the pelvi-perineal region of females.

Aim: To present an unusual case of angiomyofibroblastoma mimicking an inguinal hernia in a 62-year-old male. Material and methods: The patient was hospitalized with an irreducible, painless inguinal mass and surgical intervention for inguinal hernia was decided. The well-defined nodular mass was sent for histological examination. Results: Under microscope, proliferation of spindle and oval cells around thin-walled vessels was observed, being intermingled with mature adipocytes. We did not identify necrosis, haemorrhage, cytologic atypia or mitotic figures. The tumour cells displayed positivity for desmin, vimentin, CD34, oestrogen and progesterone receptors, a low Ki67 index and unusual nuclear positivity for c-theta (PKC $)$ ). They were negative for smooth muscle actin (SMA), S100, CD44, maspin, synaptophysin, DOG1 and CD117. The case was diagnosed as angiomyofibroblastoma, the main challenge being the differential diagnosis with aggressive angiomyxoma, which can present a similar histologic aspect and immunophenotype and recurs more frequently. No recurrences were observed 8 months after the surgery. Conclusions: Angiomyofibroblastoma should be included in the differential diagnosis of inguinal hernia. This is the fourteenth case of angiomyofibroblastoma diagnosed in males.
\end{abstract}

Key words: angiomyofibroblastoma, inguinal mass, c-theta, CD44, maspin.

\section{Introduction}

Angiomyofibroblastoma (AMF) is a rare benign myofibroblastic neoplasm which mainly occurs in the soft tissues of the pelvi-perineal region of females. Fletcher et al. described this lesion for the first time in 1992 $[1,2]$.

In this paper we present the $14^{\text {th }}$ case of AMF reported in the Medline database until the beginning of 2017, as arising in the inguinal region of a male patient $[3,4]$. The particularity of the case consists in its incidental finding in the inguinal region's soft tissue, this mass being preoperatively diagnosed as a hernial sac. The unusual nuclear expression of c-theta (PKC $\theta$ ) protein, a marker considered to be relatively specific for C-KIT negative gastrointestinal tumours (GIST) was described for the first time in the literature [5]. The criteria of differential diagnosis were also determined.

\section{Case report}

A 62-year-old male, previously diagnosed with high blood pressure, gout, haemoptysis and tuberculosis was admitted to the Surgical Department with an irreducible and painless slow growing inguinal mass.

After physical examination and ultrasonography, the case was interpreted as an inguinal hernia with indication for surgery. Laboratory tests presented parameter values within normal ranges, with slightly elevated blood uric acid: $9.52 \mathrm{mg} / \mathrm{dl}$ (normal values $=3.6-7 \mathrm{mg} / \mathrm{dl}$ ).

The patient signed consent to surgical intervention and publication of the case was obtained before surgery. During surgery, a nodular, encapsulated mass was discovered and excised along with lymph nodes from the femoral region.

The macroscopic aspect of the gross specimen revealed an encapsulated nodule measuring $55 \times 35 \times$

\section{Address for correspondence:}

Prof. Gurzu Simona MD, PhD, Department of Pathology, University of Medicine, Pharmacy, Sciences and Technology, 38 Ghe Marinescu 38 St, 540139 Tirgu-Mureş, Romania, phone: +40 745673550, e-mail: simonagurzu@yahoo.com Received: 7.08.2018, accepted: 8.08.2018. 

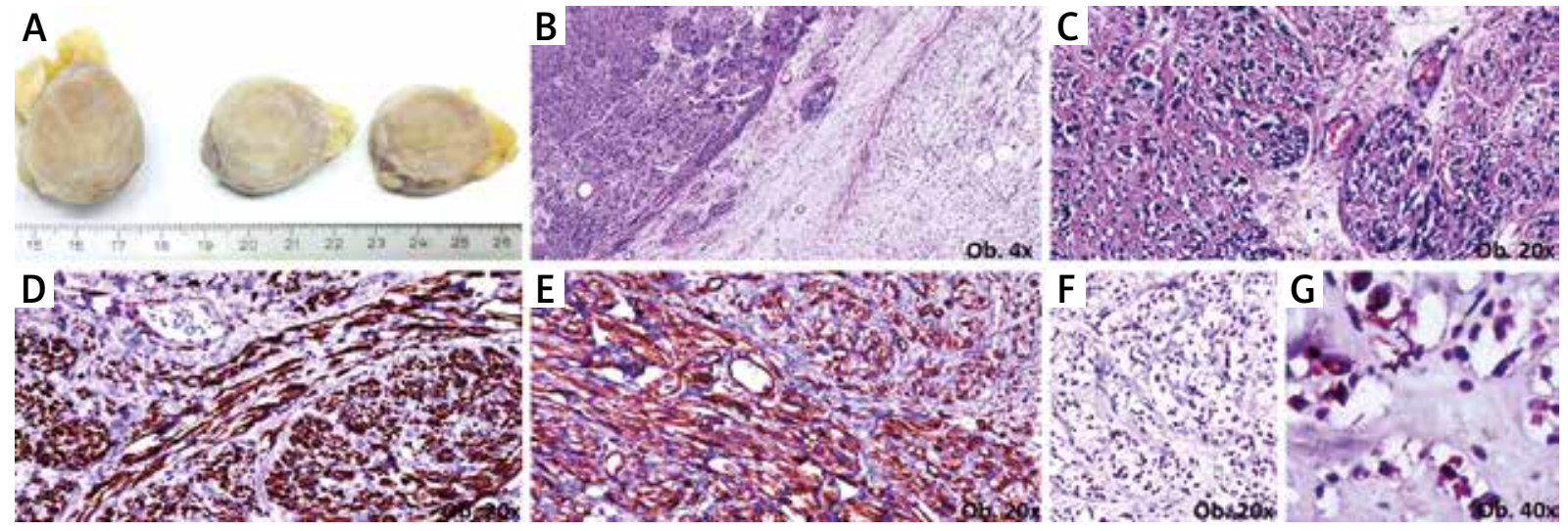

Figure 1. The angiomyofibroblastoma presented in the inguinal region of a male patient is displayed as an encapsulated solid mass with a tan colour cut surface (A). Microscopically, the well-circumscribed tumour (B) consists on small groups of round, oval-shaped and elongated cells with clear, vacuolated or eosinophilic cytoplasm and pleomorphic hyperchromatic nuclei with no nucleoli (C). The tumour cells are positive for desmin (D), CD34 (E) and oestrogen-receptor (F) and display unusual PKC $\theta$ nuclear positivity (G)

$25 \mathrm{~mm}$, with a grey, thin, smooth exterior surface and a tan colour cut surface, without haemorrhages or necroses, without infiltrating features (Figure 1).

Microscopical examination revealed a cellular proliferation with varying density, well-circumscribed by a peripheral loose connective tissue. At high-power view, the tumour was composed from round, ovalshaped and elongated cells of varying dimensions, with clear, vacuolated or eosinophilic cytoplasm, pleomorphic hyperchromatic nuclei with no nucleoli. Cells were arranged in small groups, sometimes cords, bundles and fascicles disposed around small blood vessels and were separated by connective tissue fibers. A few mature adipocytes were present, with no atypia. No necrosis, areas of haemorrhage or atypical mitotic figures were observed. The stroma was well-vascularized by small and medium-size thin-walled blood vessels and presented focal myxoid features (Figure 1).

The tumour cells displayed positivity for desmin, vimentin, CD34, oestrogen (ER) and progesterone receptors (PR), nuclear positivity for PKC $\theta$ and a Ki67 proliferation index of about $20 \%$. They were negative for smooth

Table 1. Differential diagnosis between angiomyofibroblastoma, cellular angiofibroma and aggressive angiomyxoma $[1-4,6,9-13]$

\begin{tabular}{|c|c|c|c|}
\hline Parameter & Angiomyofibroblastoma & Cellular angiofibroma & Aggressive angiomyxoma \\
\hline Gross aspects & $\begin{array}{l}\text { Well-demarcated by a thin fibrous } \\
\text { pseudocapsule }\end{array}$ & $\begin{array}{l}\text { Well-circumscribed by a thin } \\
\text { fibrous pseudocapsule }\end{array}$ & $\begin{array}{l}\text { Ill-defined, usually infiltrates } \\
\text { the surrounding tissues (may } \\
\text { present entrapped nerves, } \\
\text { muscle fibers) }\end{array}$ \\
\hline Cellularity & $\begin{array}{l}\text { Alternating hypocellular and hypercellular } \\
\text { areas; round and spindled cells } \\
\text { (plasmacytoid, epithelioid) disposed in cords } \\
\text { and nests around blood vessels; few mature } \\
\text { adipocytes may be present (in } 10 \% \text { of cases); } \\
\text { often contains mast cells }\end{array}$ & $\begin{array}{l}\text { Higher cellular density, round and } \\
\text { spindle-shaped cells distributed } \\
\text { haphazardly or in short fascicles; } \\
\text { may contain mature adipocytes (in } \\
50 \% \text { of cases); focal lymphocytic } \\
\text { aggregates and few mast cells }\end{array}$ & $\begin{array}{l}\text { Hypocellular proliferation of } \\
\text { short spindle and stellate cells, } \\
\text { radiating from vessel walls; } \\
\text { multinucleated cells may be } \\
\text { observed }\end{array}$ \\
\hline Stroma & $\begin{array}{l}\text { Oedematous, myxoid degeneration, collagen } \\
\text { fibers which separate tumour cells }\end{array}$ & $\begin{array}{l}\text { Collagenous, with thicker collagen } \\
\text { bundles, may be hyalinized }\end{array}$ & $\begin{array}{l}\text { Abundant myxoid stroma; may } \\
\text { present hematic extravasate }\end{array}$ \\
\hline Vascularisation & $\begin{array}{c}\text { Abundant thin-walled, small to medium- } \\
\text { sized vessels (capillary-type), irregularly } \\
\text { distributed }\end{array}$ & $\begin{array}{l}\text { Prominent large, larger thick- } \\
\text { walled vessels, mostly with } \\
\text { hyalinized walls and absence of } \\
\text { perivascular adipocytes }\end{array}$ & $\begin{array}{c}\text { Thin and thick-walled vessels, } \\
\text { hyalinized or hypertrophic, of } \\
\text { variable size }\end{array}$ \\
\hline Immunoprofile & $\begin{array}{c}\text { Desm+ (in all cases), ER+, PgR+, Vim+, CD34 } \\
\text { (rarely), SMA (rarely), S100- }\end{array}$ & $\begin{array}{c}\text { Vim+, Desm+/- (almost always } \\
\text { negative), CD34+, Vim+, SMA+, } \\
\text { ER-/+, PgR-/+, S100- }\end{array}$ & $\begin{array}{l}\text { Desm+, CD34+, CD44+, ER+, } \\
\text { PgR+, Vim+, S100- }\end{array}$ \\
\hline
\end{tabular}

Desm - desmin, ER - oestrogen receptor, PgR - progesterone receptor, Vim - vimentin, SMA - smooth muscle actin. 
muscle actin (SMA), S100, CD44, maspin, synaptophysin, DOG1 and CD117 (Figure 1). The femoral lymph nodes presented normal histological architecture.

Based on the clinical picture, macroscopic features, microscopic aspects and immunophenotype of tumour cells, the final diagnosis was "Angiomyofibroblastoma". The patient was discharged without any complications 10 months after surgery.

The AMF is a rare tumour and mostly occurs in females, with a female-to-male ratio of $10: 1$. In men, the tumour can occur in the pelvi-perineal region (spermatic cord, scrotum, perineum, inguinal region) but can also involve the nasal cavity and mediastinum [3, 4].

\section{Discussion}

The AMF shares many of its aspects with cellular angiofibroma (CA) and aggressive angiomyxoma (AA). Mitotic activity is absent or low in all of these lesions and due to the overlapping histological and immunohistochemical features, the differential diagnosis becomes problematic. The AMF and CA present a benign behaviour and surgical removal is mostly curative, with exceptional recurrences in cases of incomplete excision. However, as they are well-circumscribed, complete removal is not difficult to be done. In contrast, AA is ill-defined, infiltrates the surrounding tissues and presents a higher risk of recurrence (30-40\%) [6-10]. We have enumerated in Table 1 the criteria of differential diagnosis between AMF, CA and $A A[1-4,6,9-13]$.

Although a benign tumour, AA may aggressively infiltrate adjacent structures [7]. In AA without nuclear atypia and/or mitotic figures and low Ki67 index, the AA is diagnosed based on the infiltrative growth features that are absent in AMF. However, the cellular AMF is difficult to be differentiated from AA [8]. In the present case, stroma presented myxoid foci but well-defined margins and absence of recurrences allowed the diagnosis of AMF. As AMF may co-exist with AA, the correct diagnosis is sometimes established after recurrences only [8].

Differential diagnosis of AMF also includes superficial angiomyxoma, spindle cell lipoma and solitary fibrous tumour. In superficial angiomyxoma, the inflammatory cells represented mostly by neutrophils and infrequent embedded epithelial components are indicators of the diagnosis. In spindle cell lipoma, the adipose tissue is the main component and the lesion is mostly identified in the head and neck regions. In solitary fibrous tumour, the blood vessels are elongated or ramified and display a staghorn architecture [11]. A lipomatous variant of AMF with presence of adipocytes $\geq 30 \%$ and possible sarcomatous transformation was also described. The pleomorphic lipoblasts present S100 positivity and do not display positivity for $\operatorname{ER}[12,13]$.

The immunoprofile of tumour cells may also be helpful to differentiate AMF from CA and AA (Table 1). In patients with AMF, positivity of tumour cells for ER and PR may suggest a hormone-dependent tumour growth. McCluggage et al. presented the case of a 35-year-old female patient diagnosed with an ER-positive AA. The large ill-defined tumour mass infiltrating the pelvic area was incompletely excised due to the fact that the patient was not amenable to undergo further surgical interventions. This patient received gonadotropin-releasing hormone injections, a hormone that has hypoestrogenic effects and as a result, repeated magnetic resonance imaging (MRI) scans showed a continuous decrease in size of the tumour, until complete resolution [14]. Hormone therapy was not taken into consideration in our case because complete surgical excision was possible.

A question that remains unanswered in this case is the positive nuclear reaction to PKC. It usually marks the cytoplasm of c-KIT negative GISTs and is considered as a diagnostic tool for these tumours. Infrequent cytoplasmic positivity was reported for leiomyomas, schwannomas, leiomyosarcomas, and desmoid tumours [15]. This is the first report revealing PKC nuclear expression in AMF. Further studies are necessary to elucidate the significance of this positivity.

\section{Conflict of interest}

The authors declare no conflict of interest.

\section{References}

1. Fletcher CD, Tsang WY, Fisher C, et al. Angiomyofibroblastoma of the vulva. A benign neoplasm distinct from aggressive angiomyxoma. Am J Surg Pathol 1992; 16: 373-82.

2. Cheng L, Bostwick DG. Essentials of Anatomic Pathology. $4^{\text {th }}$ ed. Springer 2016; 1083-4, 1466-7.

3. Wolf B, Horn LC, Handzel R, Einenkel J. Ultrasound plays a key role in management of genital angiomyofibroblastoma: a case report. J Med Case Rep 2015; 9: 248.

4. Zhu J, Su S. Angiomyofibroblastoma of the mediastinum: a case report and literature review. Medicine (Baltimore) 2016; 95: e5484.

5. Wang C, Jin MS, Zou YB, et al. Diagnostic significance of DOG-1 and PKC- expression and c-Kit/PDGFRA mutations in gastrointestinal stromal tumours. Scand J Gastroenterol 2013; 48: 1055-65.

6. Schoolmeester JK, Fritchie KJ. Review of genital soft tissue tumors. J Cutan Pathol 2015; 42: 441-51.

7. Yu G, Kong L, Qu G, et al. Intrapelvic aggressive angiomyxoma with inferior vena cava involved. Int J Clin Exp Pathol 2016; 9: 4088-91.

8. Wang YF, Qian HL, Jin HM. Local recurrent vaginal aggressive angiomyxoma misdiagnosed as cellular angiomyofibroblastoma: a case report. Exp Ther Med 2016; 11: 1893-5.

9. Flucke U, van Krieken JH, Mentzel T. Cellular angiofibroma: analysis of 25 cases emphasizing its relationship to spindle cell lipoma and mammary-type myofibroblastoma. Mod Pathol 2011; 24: 82-9.

10. Qiu P, Wang Z, Li Y, Cui G. Giant pelvic angiomyofibroblastoma: a case report and literature review. Diagn Pathol 2014; 9: 106. 
11. Hsu C, Fang C, Chien C, et al. The first case of synchronous cellular angiofibromas of the scrotum. Urol Sci 2016; 27: 114-6.

12. Matsukuma S, Koga A, Suematsu R, et al. Lipomatous angiomyofibroblastoma of the vulva. A case report and review of the literature. Mol Clin Oncol 2017; 6: 83-7.

13. Creytens D. Cellular angiofibroma with sarcomatous transformation showing pleomorphic liposarcoma-like and atypical lipomatous tumor-like features. Am I Dermatopathol 2016; 38: 712-4.

14. McCluggage WG, Jamieson T, Dobbs SP, Grey A. Aggressive angiomyxoma of the vulva: dramatic response to gonadotropin-releasing hormone agonist therapy. Gynecol Oncol 2006; 100: 623-5.

15. Lee HE, Kim MA, Lee HS, et al. Characteristics of KIT-negative gastrointestinal stromal tumours and diagnostic utility of protein kinase C theta immunostaining. I Clin Pathol 2008; 61: 722-9. 